\title{
DEVELOPING DOMESTIC STUDENTS' INTERCULTURAL COMPETENCE-A CASE STUDY: IMMERSION PROGRAM OF SICHUAN UNIVERSITY, CHINA
}

\author{
Xianghan Liao \\ Sichuan University (China)
}

\begin{abstract}
Intercultural competence refers to the comprehensive ability required in multicultural interactions. Under the background of globalization, there is no doubt that developing students' intercultural competence is important for higher education institutions. As the number of Chinese students studying abroad has increased dramatically in recent years, most studies have focused on Chinese students' study abroad experiences and how these students adapt to different cultures, however, internationalization of education is equally important for non-mobile domestic students. In China, how to achieve internationalization at home and help domestic students to develop intercultural competence deserves more attention. University Immersion Program (UIP) in Sichuan University (SCU) is a short-term summer international program involving domestic and international students, aiming to cultivate globally competitive talents at home. By using participant observation method, the researcher participated in UIP in the role of a student and observed the interaction between domestic and international students. The observations have revealed: First, there are three main advantages of UIP - the discussion-based learning, the mixed accommodation pattern, and the cultural trips. Second, in order to better promote positive interactions between international and domestic students, proper intervention should be given to students' behavior in curricular and extracurricular activities. In conclusion, based on the method of participant observation, the study is a case analysis of UIP aiming to explore how to develop domestic undergraduate students' intercultural competence through promoting intercultural interactions in a short-term international program.
\end{abstract}

Keywords: Intercultural competence, university immersion program, internationalization at home, higher education.

\section{Introduction}

In the era of globalization, internationalization is an important topic for higher education institutions. Internationalization of higher education involves three types of students - incoming foreign students, outgoing domestic students and non-mobile students. As mobile students, the first two types have received a lot of attention from Chinese academic circles, but for the moment they are a minority in the Chinese student population. Therefore, more attention should be paid to non-mobile students.

Developing students' intercultural competence is an important way to achieve internationalization of higher education. And the cultivation of intercultural competence can be carried out through learning related courses, or exposing to multicultural contexts. Nevertheless, the latter is difficult for non-mobile students. It is because some students are unable to study abroad due to financial situation, family responsibilities, language level, etc. Besides, the interaction between domestic students and international students is very limited on campus (Harrison \& Peacock, 2010; Wang, Dai, \& Jiang, 2014). In Chinese universities, the international students' management system of accommodation and curriculum is often different from that of general domestic students, which is impeditive to their interaction on campus. And the convergence management of overseas students is hard to popularize in a short time. Therefore, it is a feasible way to promote the interaction between domestic students and international students through joint participation in short-term programs. Studies from Korea demonstrate that participation in campus programs or summer international programs can help domestic students foster interactions with international students and improve their intercultural competence (Jon, 2009, 2013). How to make increasingly popular short-term international programs play the most effective role in promoting intercultural interaction is an issue worthy of attention. 
To understand the real situation of the interactions between domestic students and international students in UIP of Sichuan University, the researcher adopted the method of participant observation as it is difficult to embody the true interactive behavior and the depth of interactions by quantitative data. The observations indicate that although a short-term international program provide students with opportunities for intercultural interactions, proper intervention is necessary to get better results.

\section{Methods}

University Immersion Program (UIP) in Sichuan University (SCU) aims to cultivate globally competitive talents at home by inviting foreign professors and experts to provide some of the best designed courses and initiating international student camps. It is a two-week short-term intercultural program and has been held for eight consecutive years since 2012.During 2019 UIP, 184 professors and more than 600 students from 144 world-class universities of 31 countries and regions were invited to experience curricular and extracurricular activities with domestic students in SCU. Joint participation in UIP is mutually beneficial for domestic and international students.

The case study of UIP was conducted by the method of participant observation. The observation method could be divided into non-participant observation and participant observation. One of the great advantages of adopting participant observation in this paper is to hide the identity of the researcher from observed objects. The researcher participated in the program and became a part of the group to observe the spontaneous behavior of the students and the depth of their interactions. The observation lasted for 10 days. The object of observation was a group of students in UIP, including four domestic students, four Russian students, one Japanese student and one Canadian student. Among them, there are six female students and four male students.

\section{Findings}

In the aspect of curriculum, the discussion organized by the professor effectively boosted the interaction among students. For example, under the guidance of the professor, domestic students put forward the stereotypes of a certain country, and the overseas student from that country explained the real situation and broke the stereotypes. In addition, the discussion was carried out on the reading material and video material offered by the professor. In addition to the group of students being observed, there were some other non-mobile students from Sichuan University in the class. It's worth noting that at the beginning of the course, students tended to sit with students of the same nationality and their attitude towards cross-cultural interaction was relatively negative, but the professor noticed this problem and intervened in students' choosing of seats. After that, students from different countries began to talk freely during break time. On the whole, the discussion-based learning was good for students' intercultural interaction.

During cultural trips, most students passively listened to the commentary provided by tour guides but have little discussion about the culture. Only one domestic student actively communicates with international students. The researcher found that the other three domestic students were not confident in their English proficiency and they tended to talk to each other in Chinese. In the regard of accommodation, double or triple rooms were randomly assigned to students with the same gender in the group. Most students directly accepted the arrangement and built good relationship with roommates, but a Russian student exchanged his room with other student when he checked in, as he wanted roommates of the same nationality. On the last day of the program, the domestic student who actively communicated with international students asked everyone for their addresses and planned to send them postcards. She experienced positive intercultural interactions and established a certain degree of friendship with international students. It is concluded that in both curricular and extracurricular activities, there are phenomena of over-reliance on the first language and imbalanced participation in intercultural communication.

\section{Discussion and implications}

First, the researcher has found due to the limited days of the program it is difficult to make students get familiar with each other and share opinions freely, which could influence their cross-cultural interactions to a certain extent. Therefore, it is necessary to intervene in their behavior. For example, teachers could rearrange students' seats and organize more discussion in class. In addition, small-group tasks can be set up in extracurricular activities, which are supposed to be performed cooperatively by a domestic student and an international student, to ensure effective cross-cultural interactions and reduce over-reliance on the first language. 
Second, previous study has indicated that the mixed accommodation pattern of Chinese and foreign students has positive effects on Chinese students' intercultural knowledge (Wang, Qu, \& Lu, 2019). However, as China is a developing country with great population, in order to enable more people to receive higher education, Chinese public universities provide inclusive, collective and cheap accommodation for all Chinese students, while overseas students have a different accommodation system. Therefore, it is difficult to popularize the mixed accommodation pattern of Chinese and foreign students in Chinese universities, but it can be applied in short-term international programs like UIP. The suggestion is to combine self-introduction activities with two-way selection of roommates between international students and domestic when implementing the mixed accommodation pattern in short-term international programs, instead of random assignment or totally free choice.

In conclusion, in order to develop non-mobile students' intercultural competence, it is not enough to put domestic and international students together through launching short-term campus programs. To avoid the tendency of students from the same country to split up spontaneously into subgroups in activities and promote positive intercultural interactions, it is of considerable necessity to give appropriate intervention to their behavior. In addition, due to the small size of observational samples and the influence of different students' characteristics, there are certain limitations in this case analysis.

\section{References}

Harrison, N., \& Peacock, N. (2010). Cultural distance, mindfulness and passive xenophobia: Using Integrated Threat Theory to explore home higher education students' perspectives on 'internationlisation at home'. British Educational Research Journal, 36, 877-902.

Jon, J.E. (2009). 'Interculturality' in higher education as student intercultural learning and development: A case study in South Korea. Intercultural Education, 20, 439-449.

Jon, J.E. (2013). Realizing Internationalization at Home in Korean Higher Education and Promoting Domestic Students' Interaction with International Students and Intercultural Competence. Journal of Studies in International Education, 17, 455-470.

Wang, H.C., \& Dai, N., \& Jiang, L. (2014). Bentusheng Guojihua: Zhongguo Gaodengjiaoyu de Xinshijiao [Interaction between Domestic and International Students in Higher Education Institutions in China]. Xiandai Daixuejiaoyu, (04), 60-66.

Wang, X.Q., \& Qu, Y.J., \& Lu, W. (2019). Butong Zhusu Moshi dui Zhongguo Daxuesheng Kuawenhuan Nengli Yingxiang Yanjiu-yi Zhongmei Wenhuazhongxin weili [The Influence of Different Accommodation Patterns on the Intercultural Competence of Chinese Post-graduate Students: A Case of the Center for Chinese and American Studies]. Bijiao Jiaoyu Yanjiu, 41(03), 31-38. 